Thorax (1974), 29, 329.

\title{
Pericardial rupture from blunt chest trauma
}

\author{
J. B O R R I E a n d I. L I C H T E R \\ Department of Thoracic Surgery, Otago Medical School, Dunedin, New Zealand
}

\begin{abstract}
Borrie, J. and Lichter, I. (1974). Thorax, 29, 329-337. Pericardial rupture from blunt chest trauma. Pericardial rupture may occur in two distinct anatomical sites, namely the diaphragmatic pericardium and the pleuropericardium. They may be combined. The problems in each type are different.

In ruptured diaphragmatic pericardium the rent may involve the pericardial cavity alone, or may extend into one or both adjoining pleural cavities. Upward herniation of abdominal viscera can occur, with or without strangulation. The presence of a pericardial rent may be suggested by diagnostic pneumoperitoneum, and chest films showing displaced abdominal viscera; its extent may be fully revealed only by thoracotomy. If the rent involves only the diaphragmatic pericardium without lateral spread into a pleural cavity, the presence of a rent may be revealed only by exploratory thoracotomy with pericardiotomy.

In ruptured pleuropericardium the rent is usually vertical and may occur on either side, more usually on the left. It may be recognized on chest films in its early stages by the presence of intrapericardial air arising from associated lung trauma. There is serious risk of heart dislocation with or without strangulation. The defect must be surgically repaired and, because of pericardial retraction, it may require a fabric patch. Teflon fabric has proved to be a long-term satisfactory pericardial substitute.

Two cases of each type of pericardial rupture are described and illustrate these points.
\end{abstract}

Rupture of the parietal pericardium is a rare yet important sequel to blunt chest trauma. It can occur in two anatomical sites, namely, the diaphragmatic pericardium and the pleuropericardium.

Rupture in each site brings its own specific problems.

\section{RUPTURED DIAPHRAGMATIC PERICARDIUM}

A tear in this situation results in a free communication between the pericardial and the abdominal cavities. The rupture may involve solely the pericardium, or may arise as a medial extension of a torn cupola of the diaphragm. Such extensions are more common on the left than on the right, as is demonstrated by the greater frequency of leftsided traumatic diaphragmatic hernia. The line of rupture may lie in a transverse, anteroposterior, oblique or L-shaped direction.

This type of rent is not usually associated with heart herniation and strangulation unless there is also a torn pleuropericardium. However, it does allow upward herniation into the pleural or pericardial cavity of stomach, bowel, or omentum. Incarceration or strangulation may occur, with acute restriction of heart and lung function. The site and size of the rent determine which serous cavity the herniated bowel will enter. If the tear involves solely the diaphragmatic pericardium, bowel may enter the pericardial cavity. If the diaphragmatic pleura is also torn, bowel may enter that pleural cavity.

\section{RUPTURED PLEUROPERICARDIUM}

In patients with rupture of the pleuropericardium, the rent is usually vertical and may communicate with the right or the left pleural cavity. The rent may be small and cause no heart herniation, or moderate in size and allow herniation of part of the heart with little or no interference with function. However, if the rent is larger, and placed several centimetres above the diaphragm, the heart may escape from the pericardial cavity into the pleural cavity and become acutely restricted in its action. 


\section{DIAGNOSIS}

In the pleuropericardial group, an unusual heart outline seen on initial chest films, or appearing in chest films some days after injury, may suggest the diagnosis. This may be confirmed by cineangiography showing the heart apex pulsating beyond its normal confines. In both groups, diagnosis of the rent may be confirmed by the radiological demonstration of air in the pericardial cavity. This may be gas in bowel herniated into the pericardial cavity, or may represent a communicating air leak from contused lung. Where no air is present diagnostic pneumoperitoneum or pneumothorax may be induced. It is possible for both types of pericardial rupture to remain unrecognized for years, even when associated with herniation of stomach or bowel, or with partial herniation of the heart.

We present in illustration four cases treated in the Southern Regional Thoracic Surgical Unit, Dunedin, New Zealand during the past 12 years.

\section{RUPTURED DIAPHRAGMATIC PERICARDIUM}

CASE 1 Mr. R. M. M., No. 44457 , a crane driver aged 42 , on 12 October 1961 was struck by a falling crane, sustaining trauma to the chest. He was shocked, with respiratory distress and severe abdominal pain. Physical examination showed tracheal deviation to the right, a rigid abdomen, dullness in the left lower chest, and diminished air entry.

Chest films showed a traumatic left diaphragmatic hernia with a distended stomach, and collapse of the lower lobe of the left lung, with marked deviation of the mediastinum to the right and compression of the right lung (Fig. 1).

The patient was taken from the admitting room direct to the operating theatre. A stomach tube was passed and copious quantities of stomach contents were removed. Catheterization showed no blood in the urine.

Operation (12 Oct. '61): Repair of ruptured diaphragmatic pericardium and left traumatic diaphragmatic hernia, and splenectomy. A left posterolateral thoracotomy was performed. Blood and blood clot were removed from the left pleural cavity, which contained stomach and omentum entering through a large L-shaped tear in the left diaphragm. The anteroposterior limb of the tear involved the whole of the left cupola; its transverse limb extended medially above the liver to involve the central tendon and diaphragmatic pericardium as far as the right cupola. There was an upward extension along the line of the left phrenic nerve which was torn free. There was thus

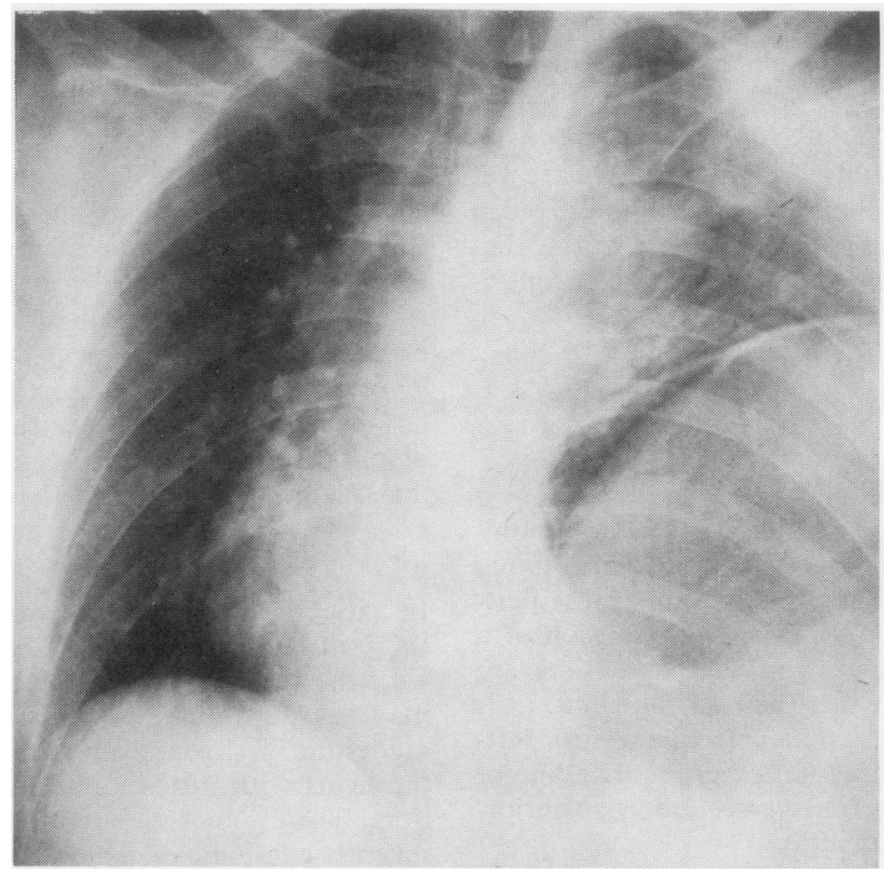

FIG. 1. Case 1. Chest film showing mediastinum displaced to the right by left traumatic diaphragmatic hernia. Thoracotomy disclosed pericardial involvement. 
free communication between the pericardial, abdominal, and left pleural cavities. Stay sutures were placed in the torn edges, and the herniated abdominal contents were inspected. The spleen was found to be ruptured and was excised. Bleeding points in the tail of the pancreas were oversewn. A second small rent in the dome of the diaphragm near the fundus of the stomach was also sutured.

The L-shaped pericardial rent and its diaphragmatic component were closed with interrupted linen sutures, as was its vertical extension. The chest wall was finally closed over waterseal drainage.

Postoperatively convalescence was slow, being complicated by persistent pyrexia, diarrhoea, and abdominal pain. The patient was discharged in good condition on 18 November 1961. Radiological examination confirmed left phrenic nerve palsy and demonstrated the presence of fractured transverse processes of the left second to fourth lumbar vertebrae. He returned to work in February 1962 and has remained well since.

CASE 2 Mr. W. J. TeW., No. 88485, a labourer aged 37 , on 2 April 1966 was knocked senseless in a car crash that broke a telephone pole. On regaining consciousness in Balclutha Hospital he had pain in the left chest, abdomen, and left shoulder tip. He coughed blood. Clinically there was generalized abdominal tenderness and guarding, more marked in the left upper quadrant. Bowel sounds were present and normal. There was no rectal tenderness. Chest examination showed diminished breath sounds with reduced vocal fremitus and resonance at the base of the left lung.

Chest films showed the stomach bubble in the left lower chest, indicating traumatic left diaphragmatic hernia (Fig. 2).

Three days later he was transferred 60 miles for further treatment.

Operation (5 Apr. '66): Repair of ruptured diaphragmatic pericardium. A left eighth intercostal space thoracotomy was performed. The diaphragm had a $10 \mathrm{~cm}$ anteroposterior tear in the angle between the left hemidiaphragm and pericardium. The left phrenic nerve was torn free. Through this rent protruded the fundus of the stomach, distended with gas, which the anaesthetist aspirated via an indwelling nasogastric tube. Thereafter the stomach was easily reduced from the left pleural cavity into the abdominal cavity.

Further inspection showed that the diaphragmatic rent also involved the pericardial cavity which freely communicated with the peritoneal cavity and the left pleural cavity. There was no heart herniation.

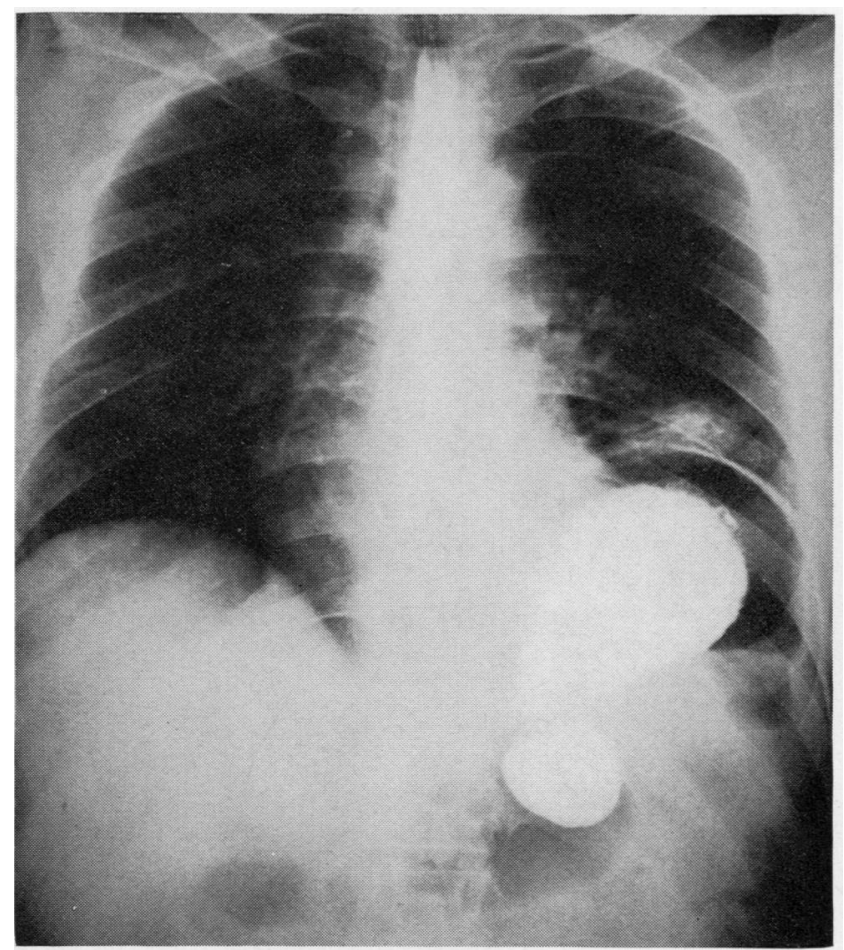

FIG. 2. Case 2. Chest film showing a traumatic diaphragmatic hernia containing stomach. 
The defect was repaired by placing 10 interrupted No. 35 linen sutures through the lower free edge of the torn pericardium. These were continued to encircle and approximate the torn edges of the diaphragm. When these sutures were tied the defect was firmly closed and the chest wall was repaired. The patient made an uneventful recovery and was discharged fit 16 days later.

\section{RUPTURED PLEUROPERICARDIUM}

CASE 3 Mr. J. J., No. 37698, aged 45, on 26 January 1961 fell 60 feet $(18 \mathrm{~m})$ from scaffolding, sustaining the following injuries:

(1) Fracture and depression of the left second to seventh ribs without pueumothorax, haemothorax or paradox but with left lung contusion; anterior fracture of the right sixth to 10th ribs;

(2) fracture of both pubic rami but with intact bladder and urethra;

(3) a double comminuted fracture of the left femur;

(4) fracture of the left os calcis.

On admission to the orthopaedic ward he was gravely shocked and 5 litres of blood and 1 litre of plasma were transfused.

Haemopericardium and traumatic left diaphragmatic hernia (Fig. 3) were suspected but no immediate action was taken.

Initially the patient made satisfactory progress, being aided by tracheostomy to assist respiration and the clearing of the tracheobronchial tree. However, the following day chest films showed enlargement of the heart shadow which appeared to be displaced to the left. The question of haemopericardium was again $\overrightarrow{\vec{A}}$ considered but pericardial paracentesis did not support this. His condition deteriorated on 28 January.

A further chest film showed the heart shadow displaced to the left (Fig. 4) but the significance of this $\frac{D}{\vec{D}}$ displacement was not then fully appreciated. $\mathrm{He} \stackrel{\mathbb{Q}}{\varrho}$ became comatose. His blood pressure continued to fall and he died on 30 January 1961.

Necropsy revealed rupture of the left pleuroperi- $\vec{O}$ cardium with dislocation of the heart into the left $\overrightarrow{\vec{H}}$ pleural cavity and cardiac 'strangulation'.

The initial chest films did not show any air in the pericardial cavity, which would have been diagnostic, $x$ and the cause of the later enlargement of the heart 0 shadow to the left was not appreciated.

CASE 4 Mr. F. S. C., No. 70102, a forestry worker 0 aged 21 , on 20 March 1971 was struck by the steering wheel of his car in a head-on collision. He was admit- $Z$ ted to Invercargill Hospital with surgical emphysema, flail left chest, left haemopneumothorax, heart trauma, respiratory failure, and tachypnoea $(60 / \mathrm{min}) . \vec{v}$

He was treated by left tube thoracostomy, tracheos- + tomy, and artificial respiration with a Bird respirator. Two litres of bloodstained fluid drained from the left pleural cavity. His admission chest film revealed fractures of the first four left ribs and surgical emphysema over the anterior chest wall, neck, and $\stackrel{\circ}{\Phi}$ axilla. Air was also seen in the pericardial cavity on $\unrhd$ the left side (Fig. 5) without evidence of enlargement $\overrightarrow{\vec{D}}$ of the cardiac outline. A chest film on 7 July 19653 was normal.

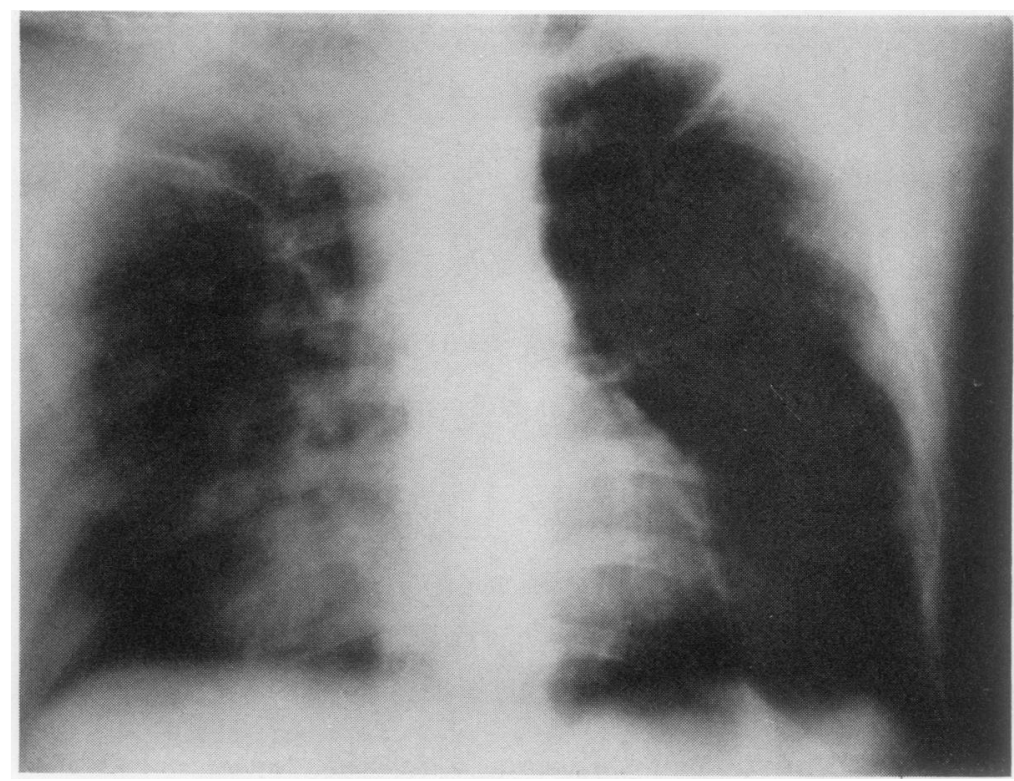

FIG. 3. Case 3. Chest film at time of injury-26 January 1961. 


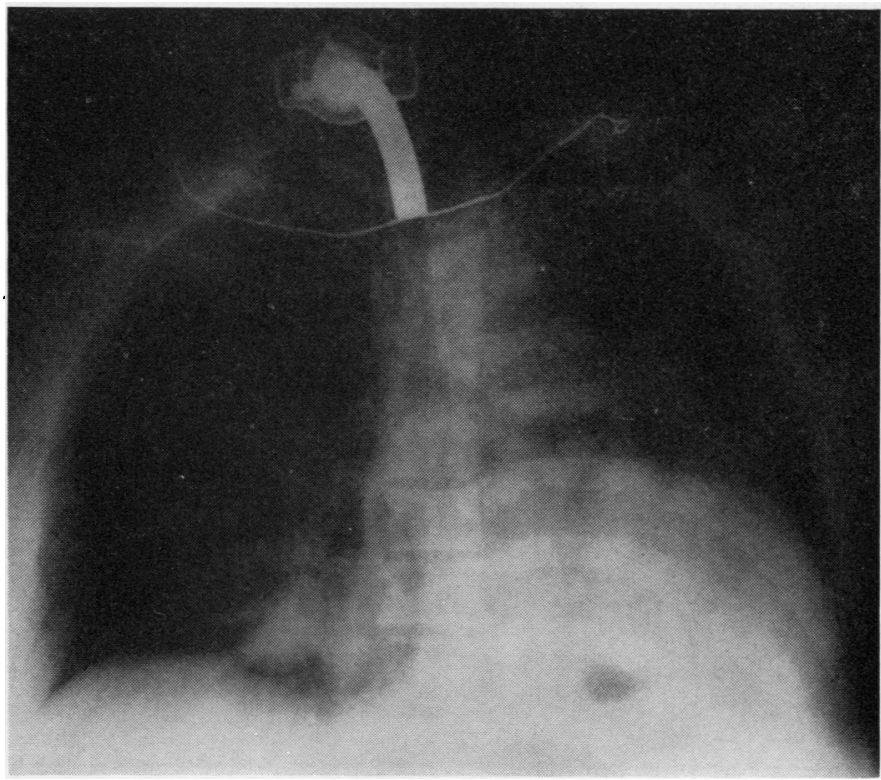

FIG. 4. Case 3. Chest film two days later showing displacement of the heart shadow to the left, later shown to be due to dislocation of the heart from the pericardium.

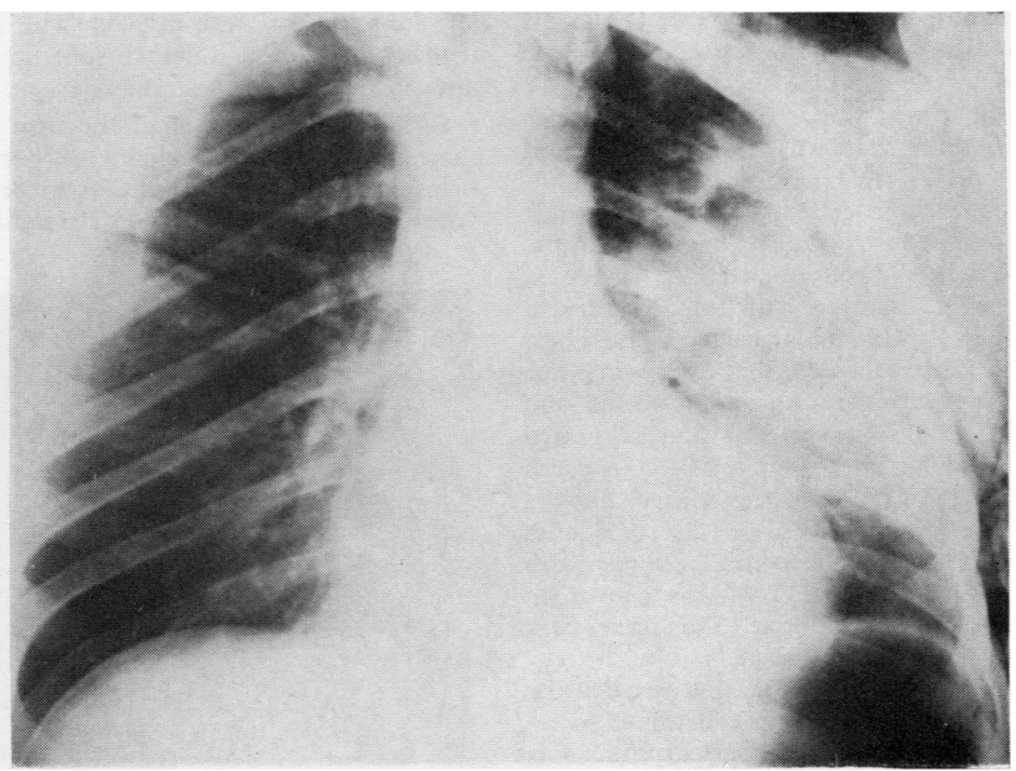

FIG. 5. Case 4. Chest film of 23 March 1971 showing traumatic 'pneumonitis' in the left lung, surgical emphysema of the left chest wall, and air lifting up the left parietal pericardium, thereby indicating the presence of a rent. 


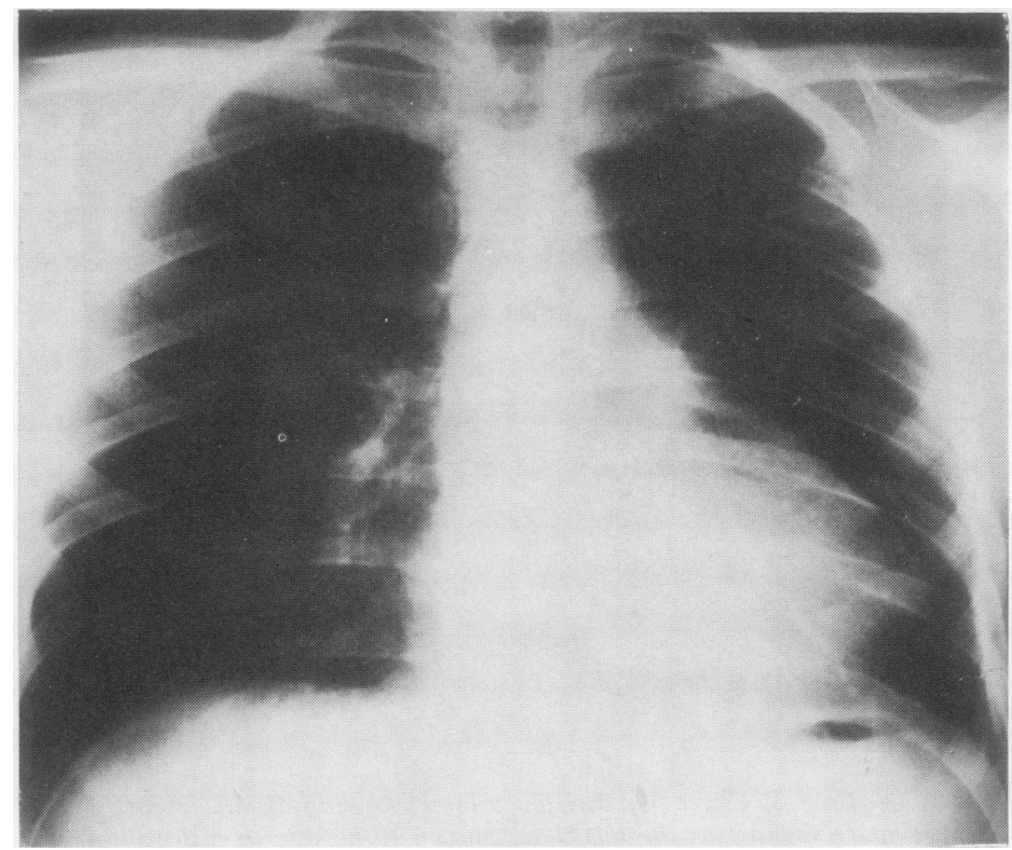

FIG. 6. Case 4. Film one week after injury, showing the heart displaced to the left; it is dislocated through the traumatic pleuropericardial rent.

Severe pain was controlled by four days of continuous epidural anaesthesia. After six days he was extubated. From admission his physician, Dr J. O'Hagan, noted an abnormal pulsation of the left chest wall.

When first seen in the thoracic surgical unit on 12 May 1971 the patient was thin, having lost 2 stones (13 kg) in weight. Pulse rate was $88 / \mathrm{min}$ and blood pressure $140 / 80 \mathrm{mmHg}$. He had a very obvious pulsation in the fourth left intercostal space in the left anterior axillary line. There were no heart murmurs. An electrocardiogram showed inverted $\mathbf{T}$ waves in leads III, aVL, and V5 and V6 with tall $R$ waves in V6, all suggesting left ventricular strain. The chest film a week after injury showed that the heart was displaced to the left with an unusual upturned and prominent apex (Fig. 6). Though this film suggested a possible left ventricular aneurysm, when considered in conjunction with the first film after injury showing air in the pericardial cavity, the film was considered to represent rupture of the pleuropericardium with partial dislocation of the heart. This was confirmed by cine-angiography which showed the apex beat herniated into the leff spleural cavity.

In order to improve fieart function and remove the risk of heart strangulation, operative treatment to replace the heart and repair the pericardium was advised.

Operation (24 May '71): Repair of ruptured left pleuropericardium and Teflon patch to pericardial defect. A left fifth intercostal thoracotomy revealed firm adhesions between the heart, pericardium, and $\vec{P}$ left lung. These were divided. The left ventricle protruded through a vertical split in the pericardium anterior to the left phrenic nerve.

Because of retraction of the torn pericardial edges, there was a large deficiency of parietal pericardium measuring $5 \times 3 \mathrm{~cm}$ (Fig. 7). In order to avoid any future heart herniation and strangulation, this defect

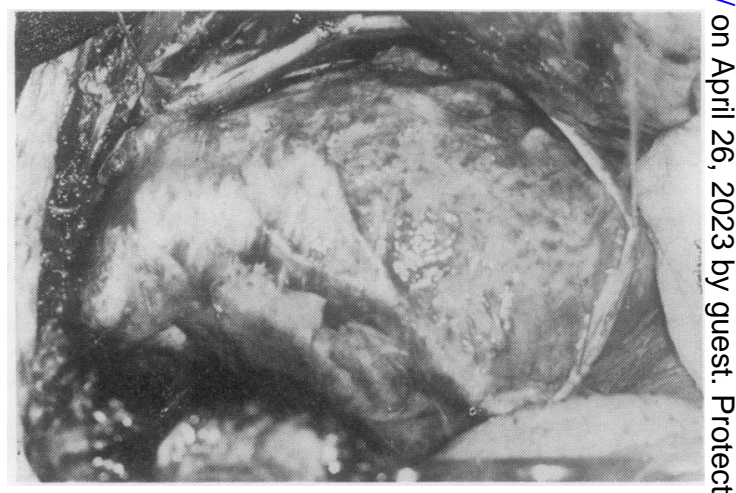

FIG. 7. The rent in the left pleuropericardium after $\stackrel{\mathbb{Q}}{\mathrm{Q}}$ freeing the heart. Note the pericardial deficiency caused by retraction of the pericardial edges. 
was patched with two layers of Teflon mesh using interrupted Mersilene sutures (Fig. 8). The patient was discharged nine days after operation.

Six months later he was fit and well and working as a supervising forest ranger. When examined two years after operation he had a degree of permanent depressed sternum. The apex beat was still in the

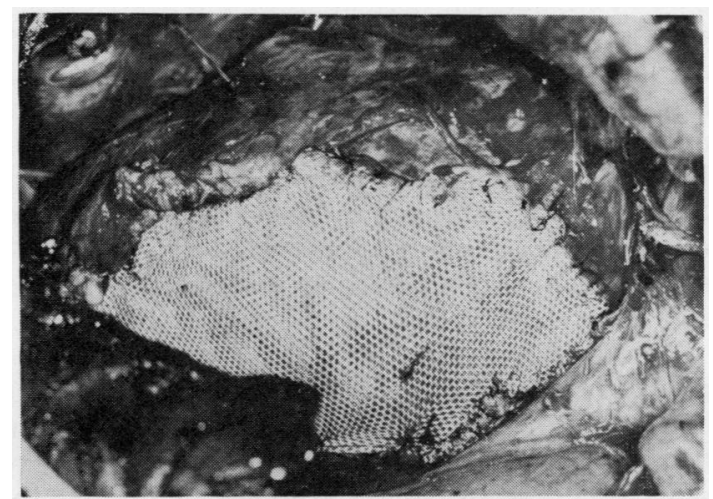

FIG. 8. The pericardial defect repaired with a twolayer Teflon fabric patch using interrupted Mersilene sutures.

fourth left intercostal space but was now within the left nipple line. The chest film was satisfactory. The electrocardiogram was normal. Lung function tests showed total lung capacity and functional residual capacity reduced by $15 \%$ of normal for his age, height, and weight.

Two and a half years after operation he continues well with his heart in the normal position.

\section{DISCUSSION}

Reports of traumatic pericardial rupture have been few with single or few examples of one or other type of ruptured pericardium. Attention has usually been focused on the diaphragm as the major structure that is damaged. Our own clinical experience suggests the need to reappraise pericardial rupture by blunt trauma and to emphasize the anatomical differences and associated pathological problems that produce two distinct clinical entities which can adversely affect heart function, often as thoracic surgical emergencies.

The exact site and extent of the pericardial rupture are dependent on the direction and force of the blow to the chest. If the diaphragmatic pericardium is injured, then there is a grave risk that abdominal contents may herniate upward into the pericardial sac to embarrass heart function by intrapericardial cardiac compression. If the pleuropericardium is torn, the heart may fall out of its pericardial sac into one or other pleural cavity, resulting in heart constriction or sudden strangulation.

Neither complication need develop on the day of injury, yet the pericardial tear may have set the stage for a later surgical emergency, as in case 3, when, possibly during turning of the patient, the heart herniated into the left pleural cavity with a fatal outcome. Awareness that such pericardial rents can and do occur following blunt trauma is necessary in order to detect and treat promptly patients suffering from this potentially lethal complication.

Keith (1910), having examined 34 diaphragmatic defects in museums of London hospitals, was the first to suggest trauma as a possible aetiological factor. Wilson, Rumel and Ross (1947) were the first to diagnose preoperatively a diaphragmatic pericardial defect by barium studies. The lesion was congenital in origin, and three-fourths of the small intestine was found within the pericardium. The diaphragmatic repair was partly by interrupted sutures to approximate the edges posteriorly, and partly by suturing the remaining edges to the anterior thoracic wall.

Crawshaw (1952) first described the repair of a diaphragmatic pericardial defect due to trauma. His patient had received a heavy blow to the lower chest one year previously, after which he had experienced episodes of intermittent intestinal obstruction with chest gurgling and vomiting. Finally, acute intestinal obstruction precipitated his admission to hospital. Physical examination confirmed moderately distended jugular veins, absent heart sounds, and absent apex beat. Chest films showed air shadows to the left of the heart.

The importance of bearing in mind the diagnosis of ruptured diaphragmatic pericardium is emphasized by Crawshaw's report of apparently negative findings at left thoracotomy until peristalsis through the pleuropericardium was observed. When the pericardium was incised, the true nature of the defect was revealed. In Robb's (1963) case, in a man who had been injured 23 years previously, a left thoracotomy showed no abnormality. A right thoracotomy was undertaken two months later when the stomach was observed through the right pleuropericardium.

In Brookes's (1953) case there was also a small defect into the left pleural cavity through which protruded omentum. Once this had been reduced, further examination of the pericardial sac revealed the pericardial rent through which stomach and omentum protruded to surround the heart. 
These defects were closed using interrupted sutures.

Although most reports have described intermittent or acute-on-chronic symptoms of intestinal obstruction, this favourable latent period is not always present. Indeed, Beddingfield (1968) reported that, when undertaking early laparotomy for a chest stab-wound, the patient suddenly developed acute tamponade during induction of anaesthesia; the blood pressure fell from 140/70 to $90 / 60 \mathrm{mmHg}$ and venous congestion occurred, followed by heart arrest requiring resuscitation by presternal compression. An immediate left anterior thoracotomy revealed the pericardial sac tightly packed with small bowel loops and omentum that had herniated through a crescentic laceration in the diaphragmatic pericardium.

Ivanov (1965) described a similar immediate herniation of bowel through a torn diaphragmatic pericardium in a 30-year-old cyclist who had crashed. The extent of the lesion was confirmed by laparotomy within an hour of the blunt abdominal trauma.

Herman and Goldstein (1965) report that the diagnosis of diaphragmatic pericardial rupture can be made preoperatively by inducing a pneumoperitoneum or by an upper intestinal $x$-ray series, especially when a gas-contrast barium meal is performed.

Crawshaw emphasizes that, in the presence of a ruptured diaphragmatic pericardium, chest films and barium meal examination may at first sight simulate a para-oesophageal hiatal hernia; but careful appraisal of the following points may lead to a correct diagnosis:

(a) history of trauma;

(b) symptoms of high intestinal obstruction;

(c) absent heart sounds;

(d) signs of pericardial tamponade;

(e) chest films showing gas shadows in a distended pericardium.

Davis (1968) reported in a 17-year-old boy traumatic rupture of the diaphragmatic pericardium, allowing early herniation of transverse colon through a large transverse rent. An abdominal approach for repair proved totally inadequate; he had to perform a left thoracotomy, opening the left pleuropericardium and then closing the rent with horizontal mattress sutures.

The effects of rupture of the pleuropericardium closely parallel those of congenital complete absence of the pericardium (Borrie, 1969), which are compatible with long life, or those with congenital partial absence of the pleuroperi- cardium where, as was described by Boxall as far back as 1886, fatal escape of the heart into the left pleural cavity may occur. Such partial pericardial defects can be surgically created, as first described by Allison in 1946, during intrapericardial resection of lung for carcinoma. By 1973 some 33 cases variously described as 'acute cardiac herniation, herniation of the heart, incarceration of the heart, volvulus of the heart, and dislocation of the heart' had been described resulting from incomplete pericardial defects left unclosed after intrapericardial resection of the lung for carcinoma (Patel, Shrivastav, and Sabety, 1973). This same danger does not occur after radical pneumonectomy with excision of all pericardium on that side, as described by Brock and Whytehead (1955).

Blunt trauma may also cause partial pleuropericardial defects, as in cases 3 and 4 . In case 3 there was a fatal outcome when the heart herniated to the left. In case 4 , though the presence of a pericardial rent was clearly indicated by demonstration of intrapericardial air in the earliest post-trauma chest film, the actual heart herniation came later. Only after restoration of good lung and chest wall function was the patient referred for surgical correction of the displaced heart. Fortunately, strangulation had been prevented by pericardial and pleuropericardial adhesions that had formed round the defect.

Reynolds and Davis (1966), in discussing injuries of the chest wall, pleura, pericardium, lungs, bronchi, and oesophagus, make the point that air may enter the pericardial space at the time of injury, as in our case 4 . Further, they stress that the effects of pericardial injury can be delayed and that radiologists must be aware of this fact.

In the repair of pericardial defects (case 4), when freeing of the heart discloses that the defect cannot be directly sutured, a Teflon or Dacron fabric patch may be inserted with excellent results. One of us (J.B.) has regularly used this $\widetilde{N}$ Dacron patch technique to close partial pericardial defects after intrapericardial resection for lung cancer.

Combined lesions of both diaphragmatic pericardium and pleuropericardium may occur. Kuzmich (1965) described a case of traumatic sinistrolateral diaphragmatic hernia and fracture of the pelvis. His patient, a 23-year-old who had fallen under the wheels of a tractor, was transferred two weeks after injury to a base hospital with intestinal noises in the left chest. At elective thoracotomy it was found that the heart had 
fallen out of the pericardium through a $15 \mathrm{~cm}$ long rent, and that omentum surrounded the heart and torn pericardium. The defect was $30 \mathrm{~cm}$ long in all, arching over the diaphragm from the costal margin to the central tendon, and extending up the left pleuropericardium. Because of the size of the defect, heart strangulation had not occurred.

In case 1 is an example of the combined type of tear; a small vertical tear extended from the diaphragmatic rent up the left pleuropericardium.

We wish to acknowledge photographic help from Mr. Gerald Brook, Mr. Brian Connor, and Mr. Donald Weston, of the Photographic Department, Otago Medical School.

\section{REFERENCES}

Allison, P. R. (1946). Intrapericardial approach to the lung root in the treatment of bronchial carcinoma by dissection pneumonectomy. Journal of Thoracic Surgery, 15, 99.

Beddingfield, G. W. (1968). Cardiac tamponade due to traumatic hernia of the diaphragm and pericardium. Annals of Thoracic Surgery, 6, 178.

Borrie, J. (1969). Congenital complete absence of left pericardium. Thorax, 24, 756.

Boxall, R. (1886). Incomplete pericardial sac: escape of heart into left pleural cavity. Transactions of the Obstetrical Society, London, 28, 209.

Brock, R. and Whytehead, L. L. (1955). Radical pneumonectomy for bronchial carcinoma. British Journal of Surgery, 43, 8.

Brookes, V. S. (1953). Intrapericardial diaphragmatic hernia. British Journal of Surgery, 40, 511.
Crawshaw, G. R. (1952). Herniation of the stomach, transverse colon, and a portion of the jejunum into the pericardium. British Journal of Surgery, 39, 364.

Davis, P. W. (1968). Traumatic herniation into the pericardial sac. Postgraduate Medical Journal, 44, 875.

Herman, P. G. and Goldstein, J. E. (1965). Traumatic intrapericardial diaphragmatic hernia. British Journal of Radiology, 38, 631.

Ivanov, V. V. (1965). Rupture of the diaphragm and pericardium in closed abdominal injury. Vestnik Khirurgii Grekova (Moskva), 94, No. 4, 109.

Keith, A. (1910). Remarks on diaphragmatic herniae. British Medical Journal, 2, 1297.

Kuzmich, V. A. (1965). A case of traumatic rupture of the pericardium in association with traumatic sinistro-lateral diaphgramatic hernia and fracture of the pelvis. Khirurgiia (Moskva), 41, 136.

Patel, D. R., Shrivastav, R., and Sabety, A. M. (1973). Cardiac torsion following intrapericardial pneumonectomy. Journal of Thoracic and Cardiovascular Surgery, 65, 626.

Reynolds, J. and Davis, J. T. (1966). Injuries of the chest wall, pleura, pericardium, lungs, bronchi and esophagus. Radiologic Clinics of North America, 4, 383.

Robb, D. (1963). Traumatic diaphragmatic hernia into the pericardium. British Journal of Surgery, 50, 664.

Wilson, A. K., Rumel, W. R., and Ross, O. L. (1947). Peritoneopericardial diaphragmatic hernia. Report of a case in a newborn infant successfully corrected by surgical operation with recovery of the patient. American Journal of Roentgenology, 57, 42.

Requests for reprints to: J. Borrie, F.R.C.S., Medical School, Box 913, Dunedin, New Zealand. 